\section{Los consorcios rurales: un análisis de los modelos normativos provinciales de Chaco, Salta y Buenos Aires}

Rural public-private partnership: an analysis of the local legal models of Chaco, Salta and Buenos Aires

\section{Haraví Eloísa Ruiz}

\section{RESUMEN}

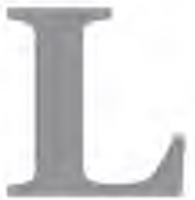

os estados provinciales argentinos utilizan estructuras consorciales diseñadas para articular actores públicos y privados en aras del cumplimiento de determinados objetivos de índole económica, o para el desarrollo de funciones típicamente de naturaleza estatal como lo son el mantenimiento de caminos rurales, de canales de riego o la distribución y control del uso del agua. En el presente trabajo realizaremos una breve descripción de las modalidades más comunes de estructuración de esta figura a nivel provincial, tomando como ejemplo normativa de Chaco, Salta y Buenos Aires. Analizaremos también sus encuadres jurídicos, la modalidad de financiamiento que prevén y su eficacia para lograr los objetivos que se proponen.

Palabras clave: consorcios rurales; articulación público-privada; desarrollo local.

\begin{abstract}
Some local states (provinces) in Argentina have been using rural public-private partnership schemes to foster local development or to decentralize activities that were originally carried by the public sector, such as the maintenance of roads, or the supply of water. This work contains a description of the most typical partnership models used by local states, like the ones created by Law 1825-I of the Province of Chaco, Law 6845 of the Province of Salta and Law $\mathrm{N}^{\mathrm{O}} 13.58 \mathrm{o}$ of the Province of Buenos Aires. Is also includes an analysis of the different legal schemes selected by theses provinces, their funding mechanisms and their ability to reach their goals.
\end{abstract}

Keywords: rural public-private partnership; local development; Argentina.
COMO CITAR ESTE ARTÍCULO Ruiz H, E. (2019). Los consorcios rurales: un análisis de los modelos normativos provinciales de Chaco, Salta y Buenos Aires. Revista de la Facultad de Ciencias Económicas, 25(2), 51-69. http://dx.doi.org/10.30972/rfce.2524565

\section{(9) $(\Theta \Theta$}

https://creativecommons.org/licenses/by-ne-nd/4.o/ Revista de la Facultad de Ciencias Económicas ISSN 1668-6357 (formato impreso) ISSN 1668-6365 (formato digital) por Facultad de Ciencias Económicas Universidad Nacional del Nordeste (UNNE) Argentina se distribuye bajo una Licencia Creative Commons Atribución - No Comercial - Sin Obra Derivada 4.o Internacional. 


\section{LOS CONSORCIOS PRODUCTIVOS DE SERVICIOS RURALES EN EL CHACO ${ }^{1}$}

La ley provincial $\mathrm{N}^{\circ}$ 1825-I (antes Ley $\mathrm{N}^{\circ} 6547$ ) define a los Consorcios de Servicios Rurales como "entidades de bien público de servicios a la comunidad, sin fines de lucro, integrados por vecinos de una zona determinada con el objeto de aunar esfuerzos y aportes económicos de distinta naturaleza para lograr contención, desarrollo y fortalecimiento de los pequeños productores chaqueños" (art. 1). La conformación de Consorcios Productivos de Servicios tiene distintos "objetivos" (art. $3^{\circ}$ ) a los que clasificaremos en tres grupos:

1) Actividades o funciones relacionadas directamente con la producción agrícola:

- Inc. a): laboreo de tierras para la producción agrícola, ganadera. Construcción de represas para reservorios de agua, desbosques, destronque y limpieza de terreno para ampliación de zonas de laboreo, acarreo de suelos para ladrilleros, y toda otra actividad o prestación de servicios que permita el fortalecimiento y desarrollo de los pequeños productores.

- Inc. b): contratar trabajos afines con reparticiones oficiales, instituciones públicas o privadas, sus socios consorcistas o con particulares.

- Inc. c): colaborar con consorcios vecinos y celebración de acuerdos bi y multilaterales con el objeto de adquirir y utilizar en común maquinarias para ejecutar trabajos.

- Inc. h): Gestionar y organizar la comercialización en forma asociada generando los instrumentos adecuados, para el acceso a los distintos mercados.

2) Actividades o funciones de programación y planificación productiva:

- Inc. d): jerarquizar modelos productivos sustentables para la agricultura familiar a partir del asociativismo y la incorporación de tecnologías apropiadas que modifiquen el atraso y marginación de los pequeños productores.

- Inc. e): planificar la producción de manera que sea previsible en volumen y calidad tanto agrícola como pecuaria y forestal que garantice una comercialización en condiciones de competitividad.

3) Actividades o funciones generales vinculadas con el medio social donde se inserta:

- Inc. f): Brindar a la comunidad circundante la atención primaria ambiental, ejerciendo la función de monitoreo, difusión y cuidado de las prácticas ambientales.

- Inc. g): Relevar las familias rurales en sus zonas de influencia, total de hectáreas existentes, actividad productiva, infraestructura predial y extrapredial y todo otro dato que coadyuve a llevar adelante los procesos productivos.

Por lo que puede observarse de la enumeración, estos objetivos constituyen más bien "funciones" o "roles" a los que se aspira que estas agrupaciones den cumplimiento. Asimismo, los Consorcios contemplados en esta ley deben ser consorcios productivos y de servicios. No pueden prestar

\footnotetext{
${ }^{1}$ Hay que aclarar que la Provincia del Chaco posee normativa específica sobre Consorcios Camineros (ley $N^{\circ} 3.565$, sancionada en el año 1990).
} 
cualquier servicio, sino aquellos que se vinculen con lo rural. Sin embargo, cuando observamos la variedad de actividades que pueden ( $y$ deben) desplegar, vemos que en realidad el objeto que tienen es mucho más amplio de lo que nominalmente la figura pareciera indicar: en efecto, no podría considerarse -por ejemplo- que las actividades de relevamiento de familias rurales o difusión de prácticas ambientales puedan entenderse estrictamente como servicios productivos.

En cuanto a los socios, el art. 7 contempla tres categorías: el socio consorcista activo, persona física, propietaria, arrendataria $\mathbf{u}$ ocupante de tierras ubicadas en el ámbito rural de la jurisdicción del Consorcio, puede integrar los distintos órganos del gobierno y tendrá voz y voto en las decisiones; el socio consultor técnico de representación necesaria, persona física que actúa en nombre del o los Municipios y del Ministerio de la Producción, quien ocupará una de las vocalías titulares de la Comisión Directiva con voz y voto en la toma de decisiones, al igual que en la Asamblea General, y el socio consorcista adherente, que podrá ser una persona física o jurídica, pública o privada que posea intereses dentro de la jurisdicción del Consorcio, originados en el ejercicio de sus actividades normales, quien tendrá sólo voz en la Asamblea General, pero no podrá ocupar cargos en la estructura.

Se puede inferir de ello una clara intención de dar amplia participación a los sujetos privados en la toma de decisiones y actividades de la figura, donde también se cuenta con la "pata estatal". Al mismo tiempo, la configuración de las diversas categorías de miembros favorece una conformación consorcial representativa del sector productivo involucrado.

En cuanto a los órganos de gobierno, se establece una Asamblea General de Socios, una Comisión Directiva, un Comité Ejecutivo y una Comisión Revisora de Cuentas, siendo el Decreto Reglamentario el que detalla los requisitos que deben reunir sus miembros en cada caso.

La zona de influencia del ente, llamada "jurisdicción del consorcio" por la norma, no podrá ser menor a 500 hectáreas, y la entidad no podrá estar conformada por menos de 25 miembros. Además, ésta deberá definir con claridad la finalidad de la constitución del consorcio por vía estatutaria. En este sentido vale aclarar que se prevé la creación de un "Estatuto Tipo" por parte del Organismo de Aplicación de la ley, a utilizarse en la conformación de estas organizaciones.

Adicionalmente, el Estado Provincial podrá hacer observaciones acerca de las cantidades máximas de hectáreas de las que podrá ser titular un asociado para pertenecer al consorcio, buscando salvaguardar de este modo prioritariamente los intereses de los pequeños productores (Ruiz, 2017).

Las disposiciones señaladas precedentemente dan cuenta del fuerte enlace y vinculación territorial que se procura mantener entre la figura asociativa y su entorno de inserción, siendo esta también una de sus notas características (Ruiz, 2017).

El financiamiento de la constitución y funcionamiento de los consorcios rurales se lleva a cabo a través de la creación de un "fondo específico", compuesto por diversas fuentes de recur- 
sos, la mayoría provenientes de impuestos provinciales al agro (Art. $9^{\circ}$ incs. a, b y c) ${ }^{2}$, ciertos fondos nacionales (inc. $\mathrm{d} \mathrm{y} \mathrm{g})^{3}$, del producido de toda obra o trabajo que realice en su carácter de Consorcio a productores no asociados o particulares (inc. g), más los aportes ordinarios o extraordinarios de los miembros del consorcio (inc. h).

Es oportuno aclarar que la transferencia de los recursos provenientes de las arcas públicas (impuestos nacionales y provinciales y demás fondos públicos) tenía inicialmente un "tope legal" de 20 millones anuales para el sistema en su totalidad, monto que luego fue ampliado a 50 millones en el año 2013 y que a partir del 2018 se encuentra en 80 millones de pesos.

Estos recursos de origen estatal, a su vez, deben ser repartidos en dos fondos destinados a la ejecución de los objetivos de los consorcios en funcionamiento (Fondo A, formado por el $80 \%$ de estos recursos) y a la formación de otros nuevos (Fondo B, formado por el 20\% restante).

Finalmente y no menos importante es la calificación jurídica que dicha ley le imprime a esta figura: la de las Asociaciones Civiles, debiendo inscribirse como tales en la Dirección de Personas Jurídicas y a los fines de la conformación de esta figura especial, en el Ministerio de Producción. Esta definición legal sobre la naturaleza de la figura bajo análisis nos lleva a tratar algunos puntos relativos a dicho carácter, principalmente a partir del art. 149 Código Civil y Comercial (en adelante CCC).

Sabemos que las Asociaciones Civiles deben contar con patrimonio propio en virtud de lo establecido por el art. 154 CCC. Sostiene Boretto (2015) que:

"El patrimonio de la entidad sirve para el cumplimiento de sus fines y es distinto del de cada uno de sus miembros, pudiendo soportar sus propias deudas y responsabilidades. Es una consecuencia, claro está, del principio de personalidad diferenciada [art. $143 \mathrm{CCC}$. Por consiguiente, los bienes de la entidad figuran en su propio patrimonio y no en el de los individuos que la integran" (p. 299).

Ahora, ¿el "fondo específico" que prevé la ley provincial constituye el patrimonio de las asociaciones civiles "consorcios"? En caso de serlo, ¿cumple éste con las características conceptuales de "patrimonio social", en los términos exigidos por la legislación civil? Recordemos que desde el punto de vista legal, toda persona jurídica debe poseer un patrimonio, el que no se confunde con el de los individuos que la conforman. Como sostiene Boretto (2015) "(...) dado que para el derecho argentino el patrimonio es un atributo de la persona, si la persona jurídica careciese de todo patrimonio, se le estaría negando su propia personalidad" (p. 299).

En este sentido cabe enfatizar que el fondo específico que establece la ley está conformado casi totalmente por recursos que provienen de impuestos provinciales (incisos a y b del art. 9) y fondos creados por leyes nacionales, como el Fondo Algodonero Nacional (inc. d), o locales

\footnotetext{
${ }^{2}$ Art. $9^{\circ}$ Inc. a) El setenta y cinco por ciento (75\%) de la recaudación del Impuesto Inmobiliario Rural. Inc. b) El treinta y cinco por ciento (35\%) de los pagos a cuenta por traslado de la producción primaria que no se hayan compensados con impuestos provinciales. Inc. c) El cincuenta por ciento (50\%) de los fondos determinados por la ley 5755 y sus modificatorias, resguardando los derechos que la misma otorga a las comunidades indígenas.

${ }^{3}$ Art. 9 Inc. d) El veinte por ciento (20\%) del Fondo Algodonero Nacional. Inc. e) Todo otro recurso nacional o provincial que se destine al presente régimen.
} 
como el de Asistencia No Reintegrable a Productores Criollos y Aborígenes (inc. c), y en menor medida -casi simbólicamente- por el aporte de dinero en efectivo por el pago de cuotas sociales normales y extraordinarias que efectúen los socios. Asimismo lo compone también el fruto de toda obra o trabajo que ejecute el consorcio a productores no asociados o particulares.

Hay que agregar que el Decreto Reglamentario avanza sobre lo dispuesto en la ley sobre estos recursos, estableciendo con qué parámetros se distribuirán los fondos públicos provinciales y nacionales recaudados, aclarando las afectaciones especiales que los consorcios están constreñidos legalmente a respetar y por tanto deberán dar a parte de esos fondos, en el marco del desarrollo de su actividad. En otras palabras, si bien la ley establece que el manejo de estos fondos lo tendrá (una vez transferidos desde la Provincia) cada ente, la reglamentación del art. 9 dispone una serie de destinos específicos que deben darse a gran parte de esos recursos públicos. A modo de ejemplo, los recursos provenientes del inc. d) de la ley (Fondo Algodonero Nacional) deberán aplicarse exclusivamente al cultivo de algodón por parte de los Consorcios. Asimismo, el inc. e) que se refiere a los recursos nacionales aplicados a agricultura familiar, debe ser destinado a la actividad productiva de la agricultura familiar exclusivamente (Ruiz, 2017).

Observamos que estas afectaciones parciales que direccionan el uso de una porción importante de los recursos, provocan una limitación importante a los consorcios, quienes ven acotada su libertad de decidir el destino que prefieran para los fondos públicos que reciben y que constituyen la porción principal de sus patrimonios. Ello es comprensible desde el punto de vista de la Administración Pública, que arrastra los condicionamientos inherentes a estos fondos nacionales o provinciales afectados al fomento de actividades específicas, no pudiendo disponer mediante un Decreto el redireccionamiento de los mismos. Sin embargo, desde el punto de vista de la normativa aplicable a las Asociaciones Civiles, éstas plantean una restricción seria a las posibilidades de administración y disposición del patrimonio, cosa que provoca -al menos- un importante desdibujamiento de la figura jurídica.

En este sentido, quizás hubiese sido mejor pensar en la estructuración de los consorcios bajo alguna figura legal de Derecho Administrativo antes que bajo la forma de Asociaciones Civiles. De hecho, el artículo 2 que otorga tal carácter a los consorcios fue uno de los artículos más debatidos antes de la aprobación la ley4. Otra opción hubiese sido financiar el sistema con recursos que no estén gravados con afectaciones específicas, o a través de la creación de cargas particulares destinadas al financiamiento del sistema (Ruiz, 2017).

En segundo lugar debemos decir que la imputación del 20\% del total de los recursos públicos para la formación de nuevos consorcios (llamado Fondo "B" por el art. 10 última parte), cuando el sistema completo cuenta con un fondeo que se liquida anualmente y que no podrá superar actualmente los 80 millones de pesos, luce excesivo y sólo se justifica en una primer etapa de implementación de la ley. 
Si se piensa en el modo de implementación de los dos fondos, observaremos que lógicamente el aumento del número de consorcios significa menos fondos para los ya existentes, dado que el monto a repartir es "fijo", "anual" y dispuesto discrecionalmente por el Ejecutivo, ya que la ley no establece un mecanismo que obligue a incrementar el financiamiento a medida que ingresen nuevos integrantes al sistema. En consecuencia, el "total" a repartir entre 10 o 100 consorcios es siempre el mismo. Tal vez hubiera sido mejor destinar tal porcentaje para la constitución solo hasta la formación de determinado número de consorcios o hasta lograr determinada "presencia territorial" de éstos a lo largo y ancho de la provincia, y luego acotar el porcentaje del Fondo B y destinar un mayor monto al Fondo A, dedicado a solventar el funcionamiento de los ya constituidos. ${ }^{5}$

Asimismo, aun cuando -como veremos- este no es un problema exclusivo de los consorcios chaqueños, la estructuración de los recursos así dispuesta nos hace reflexionar sobre la escasa posibilidad de sobrevivencia y sustentabilidad de los consorcios en ausencia de los aportes públicos dada su importancia en la conformación de estas estructuras (Ruiz, 2017), y pese a que el sistema tiene por fin "el fortalecimiento institucional de las estructuras asociativas intermedias del sector", de acuerdo a lo anunciado en oportunidad de su sanción legislativa.

Finalmente, debemos señalar que si se tiene en cuenta la cantidad de participantes ${ }^{6}$, el fondeo total del sistema resulta sumamente exiguo, aun en el caso que funcionase plenamente (lo que no ha sucedido con regularidad). ${ }^{7}$

\section{LA LEY PROVINCIAL DE SALTA N ${ }^{\circ} 6.845$ SOBRE "PRINCIPIOS PARA LA ORGANIZACIÓN DE LOS CONSORCIOS"}

Esta norma define a los Consorcios como "entes públicos no estatales constituidos por personas físicas o jurídicas ligadas entre sí por un interés particularmente intenso vinculado a la construcción y/o mantenimiento de una obra y/o a la prestación de un servicio y/o a la realización de una actividad de notoria utilidad social". Estas obras o actividades, dice la ley, deben presentar un interés público "objetivo". Asimismo, cabe aclarar que desde el 2006 los consorcios que regulan el uso del agua se rigen por una norma especial, aunque siempre con arreglo a esta ley general sobre la figura. ${ }^{8}$

\footnotetext{
${ }_{5}^{5}$ Se puede leer en la transcripción taquigráfica de la sesión ordinaria que este es uno de los objetivos centrales que tuvo el cuerpo legislativo con la sanción (unánime) de esta normativa. Fuente: http://www.legislaturachaco.gov.ar/sitio/paginas. php?pag_id=6 (págs. 65 y 66).

${ }^{6}$ De acuerdo a las últimas informaciones disponibles en los medios, Chaco contaba para 2017 con más de 94 consorcios productivos, en los que participan aproximadamente unas 15.000 familias.

${ }^{7}$ A modo de ejemplo, en el año 2016 el sistema recibió un total de 8 millones, apenas un $20 \%$ del monto idealmente estipulado para su financiamiento, cifra que se encuentra muy por debajo del tope previsto por la ley.

${ }^{8}$ Salta prevé los Consorcios de Usuarios en su Código de Aguas (Ley 7017/006).
} 
A diferencia de lo establecido en la ley chaqueña, en este caso es el Gobernador o los Intendentes quienes evalúan la realización de una convocatoria dirigida a personas físicas o jurídicas de "excelentes antecedentes o reconocido prestigio" para que tomen a su cargo la realización de alguno de los objetos enunciados, que debe estar enunciado en la convocatoria, aunque la norma fue flexibilizada por el Decreto que la reglamenta. ${ }^{9}$

En cuanto a su estructuración y naturaleza, el art. $4^{\circ}$ de la ley establece que separación de la persona jurídica "consorcio" de la de sus miembros, quien como tal tiene capacidad para celebrar todos los actos jurídicos tendientes a la consecución de su objeto. Según la norma, y a diferencia del caso chaqueño, la naturaleza jurídica de estos entes será el de una persona jurídica de "Derecho Público no Estatal", la que se adquiere a partir de un acto administrativo del Gobernador o de los Intendentes, mediante la aprobación del acta de constitución de los mismos y fijando sus vías de financiamiento (art. $8^{\circ}$ ).

Como señala Boretto (2015) al comentar el art. 146 del nuevo Código Civil y Comercial de la Nación:

La doctrina del derecho administrativo ha impuesto la noción de ente público no estatal para explicar la naturaleza de algunas personas que, aunque ejercen algún tipo de función pública, están integradas por particulares y, en su constitución, el Estado puede o no haber tenido injerencia decisiva. Estas personas desempeñan funciones que, directa o indirectamente, se vinculan con los fines del Estado, y este carácter "público" las distingue de las entidades que se rigen exclusivamente por el derecho privado. No están enumeradas en el CCC, pero su existencia está fuera de toda duda (p. 292).

El procedimiento para el otorgamiento de la personalidad jurídica está sometido a la inscripción del ente en un registro -dependiendo el objeto que aquel tenga $\mathrm{a}^{10}$ - y a una publicación. Su funcionamiento interno se deja librado a la configuración de las partes, mientras que se respeten algunos lineamientos mínimos. Así lo expresa el art. 6 de la norma citada:

"Los consorcistas serán libres de en la determinación de la forma con arreglo a la cual se organizarán, observándose, empero, los siguientes dos principios generales: a) El o los titulares del interés predominante constitutivo del objeto del consorcio constituirán el órgano de administración y gobierno del mismo. b) El o los titulares del interés menos predominante constituirán el órgano de control del consorcio. Tales principios generales deberán exteriorizarse en el instrumento de la constitución, sin perjuicio de los otros contenidos del mismo". (Art. 6 Ley Nº 6.845).

\footnotetext{
${ }^{9}$ El Decreto Reglamentario 953 de 1998 establece en su art. $1^{\circ}$ que también las personas físicas y jurídicas pueden hacer llegar al Gobernador o Intendente una "breve y clara descripción de la necesidad pública de competencia estatal" que consideren que están en condiciones de satisfacer a través de la formación de un Consorcio, para que aquellos evalúen la pertinencia y efectúen la convocatoria que establece la ley.

${ }^{10}$ La norma establece en su art. $5^{\circ}$ que los registros serán llevados por los Ministerios de Producción y Empleo en el caso de los consorcios con objeto productivo, por el Ministerio de Salud si está vinculado a la satisfacción de intereses comunes vinculados a la salud, por las Municipalidades en el caso de obras vecinales o por la Secretaría de la Gobernación en el caso de los consorcios vinculados al Sistema de información de la provincia.
} 
Al ser una norma general, contempla la posibilidad que estos entes puedan tener objetos de muy diversa naturaleza (art. $10^{\circ}$ ), como:

- la construcción, mantenimiento y conservación de caminos; de obras hidráulicas de riego o agua potable; de obras vecinales en general (pavimentación, desagües, espacios verdes), de divulgación y utilización de técnicas para la mejora de la producción;

- la prestación de servicios vinculados a la salud pública;

- la investigación y profundización de los conocimientos.

Como se puede observar, la ley salteña enumera una serie de objetos que no se limitan a la prestación de servicios ni se circunscribe a las actividades rurales, sino que abarca también la ejecución de obras determinadas y la investigación. A su vez, no se pretende que éstos cumplan objetivos vinculados al desarrollo económico o social.

Además, a diferencia de los consorcios de servicios rurales chaqueños, los consorcios salteños que pretendan formarse, deben tener al momento de su constitución un objeto y actividad concreta y bien delimitada. Asimismo, al menos los destinados a la realización de obras, poseen una vida limitada en el tiempo: la de la duración de la obra que constituye el motivo de su constitución.

En cuanto al financiamiento del sistema, éste también es un sistema que depende completamente de mecanismos de financiamiento y recursos públicos. En efecto, la ley salteña establece que los consorcios pueden "fondearse" por dos vías que no son excluyentes: a través de recursos indicados en la ley de presupuesto u otras normas específicas, o vía la implementación de mecanismos por contribución de mejoras ${ }^{11}$, bajo la órbita provincial o municipal, dependiendo del origen de la iniciativa y la ubicación de la obra o el servicio (art. $13^{\circ}$ ).

La modalidad del financiamiento debe ser dispuesta por Decreto, Ordenanza Municipal o en licencia habilitante (art. $21^{\circ}$ ), y la recaudación estará a cargo de los órganos estatales provinciales o municipales, e incluso puede disponerse que la recaudación la lleven a cabo los propios consorcios.

Como se puede observar, aquí la figura del consorcio tiene como interés inmediato la articulación público-privada para la realización de alguna actividad determinada (de obra o servicio) que reporte interés público, y no la de lograr la contención, desarrollo y fortalecimiento de un sector (los pequeños productores rurales, en el caso de la ley chaqueña). ${ }^{12}$

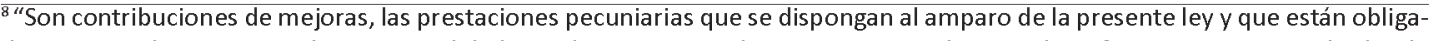
dos a pagar a la provincia, a las municipalidades y a los consorcios, las personas que obtengan beneficios o mejoras en el valor de sus bienes inmuebles como consecuencia de obras o servicios públicos. También lo serán quienes reciban beneficios apreciables en dinero como consecuencia de una actividad o de los servicios prestados por éstos ${ }^{\prime \prime}$ (art. 15 ${ }^{\circ}$ ). Esta contribución total de todos los contribuyentes no puede exceder el total del costo de la obra (art. $17^{\circ}$ ), ni el valor individual de cada contribución puede exceder el 33\% del valor fiscal del inmueble obligado al pago (art.18\%). El Decreto Reglamentario 953 de 1998 dispuso en su art. $13^{\circ}$ que previo al establecimiento de la contribución, será necesario convocar a una audiencia pública para explicar la naturaleza y costo de la obra o del servicio. Asimismo, la determinación del monto de la contribución deberá determinarse con la intervención con la intervención de las Universidades Públicas y el resto de las partes en audiencia pública.

12 Sin embargo, el Decreto Reglamentario, en una confusa redacción incluye al final del mismo que "Constituye uno de los fines de la Política de constitución de los consorcios la creación de puestos de trabajo en la Provincia y la novación de las relaciones de empleo público en relaciones contractuales reguladas por el Derecho del Trabajo", lo cual demuestra una contradicción (o al menos confusión) con los objetivos que inspiran la ley que reglamenta.
} 
Ambas figuras parecen entonces estar inspiradas por principios diferentes: mientras que se infiere de la ley chaqueña el propósito (por lo menos formal) de acompañar desde lo público en el fortalecimiento y búsqueda de sustentabilidad del sector de pequeños productores rurales, el consorcio diseñado por la norma salteña parece inspirarse en la ideología de descentralización y en la delegación de funciones propiamente estatales en entidades privadas, diseños que, como veremos a continuación, son propios de la década en la que esta legislación fue sancionada.

\section{LOS CONSORCIOS DE GESTIÓN Y DESARROLLO BONAERENSES}

Otro diseño que parece tener rasgos de los dos modelos precedentes, con una estructura y sistema de financiamiento similar al modelo salteño, pero con una orientación más cercana al modelo chaqueño, es el de los Consorcios Productivos (hoy Consorcios de Gestión y Desarrollo) de la Provincia de Buenos Aires, cuya configuración actual se introdujo mediante la ley 13.580 del año $2006^{13}$. Esta ley derogó el art. 43 de la Carta Orgánica de las Municipalidades, donde originalmente estaban contemplados (Decreto Ley 6.769/58 reformado por ley 12.288 de 1999).

Se los considera con personería propia y plena capacidad jurídica y aunque no lo aclare expresamente, dada su conformación, constituyen personas jurídicas de Derecho Público. Asimismo, no se establece expresamente el o los objetos posibles la figura, aunque de la lectura general de la norma se infiere que pueden serlo actividades productivas, y la experiencia que antecede a su sanción indica que se tratan de actividades productivas relacionadas con lo agropecuario y actividades conexas. ${ }^{14}$

$\mathrm{El}$ art. $2^{\circ}$ dispone que además de la actividad que tengan por objeto estos entes, deberían adicionalmente cumplir con otras funciones, como las de propiciar la radicación de pequeñas, medianas y microempresas en sus regiones; propender al logro de una mayor competitividad y a un crecimiento armónico de las regiones; facilitar a los productores y demás actores del sistema la información y/o capacitación necesaria para llevar a cabo con éxito los proyectos productivos; fomentar y arbitrar los medios que permitan a los productores un fácil acceso a nuevas tecnologías; fomentar la asociación de productores e industriales bajo las formas jurídicas para gestionar la comercialización de productos, bienes y servicios; impulsar la constitución de un Foro de Concejales en cada consorcio que permita unificar criterios para una legislación común en aquellos aspectos que le sea posible, entre otras.

\footnotetext{
${ }^{13}$ Articulo 1. "Son Consorcios de gestión y desarrollo los constituidos por varios Municipios entre sí, o entre uno o más Municipios con la Nación, la provincia de Buenos Aires, una o varias personas de existencia ideal de carácter privado o público que se encuentren ubicados dentro del ámbito territorial de la provincia de Buenos Aires, o con personas físicas o entes estatales descentralizados. La constitución y funcionamiento se regirá por las disposiciones de la presente ley, sus estatutos orgánicos, las normas generales y especiales vigentes y las normas que las modifiquen o sustituyan. Los Consorcios tendrán personería propia y plena capacidad jurídica".

${ }^{14}$ En efecto, Posada ( $\mathrm{s} / \mathrm{f}$ y 1990 ) determina que en su mayoría de focalizaron en porcinocultura, horticultura bajo cubierta y apicultura.
} 
En este punto, esta estructura prevista por la ley bonaerense se asimila a la norma chaqueña, estableciendo que además del objeto u objetos propios que cada consorcio posea, éstos deben desarrollar actividades vinculadas con el desarrollo económico y social.

En cuanto hace a las capacidades jurídicas de estas estructuras, de acuerdo al art. $4^{\circ}$ los consorcios bonaerenses podrán -siempre en aras del cumplimiento de sus objetivos-, tomar créditos de organismos oficiales o privados, internacionales, nacionales o provinciales; asociarse con la actividad privada; otorgar crédito a personas físicas o de existencia ideal para emprendimientos que tengan directa relación con su objeto con fines de asistencia, promoción, y fomento; debiendo los estatutos de cada consorcio establecer las pautas por las cuales se evaluarán los requisitos, realizar compras.

En relación con su estructura el art. $6^{\circ}$ establece que deberán dictarse sus propios estatutos, precisando la adopción de la figura establecida por esta ley, sus normas de funcionamiento, detallando la participación que corresponda a cada Municipio integrante, el destino de sus bienes en caso de disolución, y los derechos y obligaciones de aquellos integrantes del consorcio que se retiren o ingresen a un consorcio ya constituido. Este documento deberá pasar por un control de la Asesoría General de Gobierno y deberán inscribirse en un Registro habilitado al efecto por la autoridad de aplicación (art. $7^{\circ}$ ).

Deberán además prever un Consejo de Administración con funciones de órgano de gobierno y administración; debiendo atribuir la representación del ente a uno o más miembros del Consejo, con los alcances que se establezcan en los propios estatutos (art. $6^{\circ}$ ).

En relación a los mecanismos de financiamiento de estas estructuras, el art. $10^{\circ}$ establece que la provincia podrá disponer la destinación de una partida presupuestaria especial, y según el art. $11^{\circ}$, los fondos destinados a programas desarrollo productivo y creación de empleo otorgados por la Provincia, la Nación u otros organismos nacionales o internacionales, podrán ser canalizados por los Consorcios de Gestión y Desarrollo, según las prioridades que establezca el órgano rector del consorcio y según lo dispongan sus respectivos estatutos.

Al igual que en los otros casos, la provisión de fondos para el funcionamiento de estas estructuras proviene esencialmente de partidas presupuestarias estatales, a la vez que no se prevén mecanismos o formas de "desacople" o "despegue" económico paulatino para un futuro.

\section{CONSIDERACIONES FINALES: ESTRUCTURACIONES DIVERSAS, PROBLEMAS SIMILARES}

Resumiendo entonces, vimos en primer lugar que los Consorcios Productivos de Servicios Rurales Chaqueños pretenden constituirse en herramientas aptas para desarrollo local, 
coordinando el trabajo de los productores y la población rural, con una gran injerencia y un importante aporte logístico por parte del estado provincial (Ruiz, 2017).

El perfil que quiere otorgársele a la figura es el de una organización que gestiona, acompaña y controla la ejecución de las transacciones en la que intervienen sus miembros. Además, si bien la figura del "consorcio"-en su concepción tradicional- es utilizada para emprendimientos temporarios o niveles de cooperación en ciertas fases del proceso de producción, el Consorcio de Servicios Rurales chaqueño constituye un instrumento que diseña una estructura con vocación de permanencia en el tiempo y personería jurídica (Ruiz, 2017). Sin embargo, dichos objetivos pueden verse obstaculizados por algunos rasgos contenidos en la misma ley.

En primer lugar, la naturaleza de Asociaciones Civiles atribuida por la ley a los consorcios parece no ser una elección del todo adecuada de acuerdo a la forma en que se estructura el régimen. ${ }^{15}$

En segundo lugar, y aun en el caso en que consideremos conveniente el encuadramiento elegido por el legislador provincial, la modalidad de financiamiento seleccionada posee -a nuestro criterio- tres falencias importantes: 1) es demasiado dependiente de los fondos que provee el Estado; 2) se estructura en base a un esquema que no instrumenta mecanismos que tiendan progresivamente a mejorar la auto-sustentabilidad de las estructuras asociativas privadas, lo que representa un punto débil del diseño, ya que todo el régimen y su supervivencia queda expuesto y vulnerable a los vaivenes políticos ${ }^{16}$ (Ruiz, 2017) y 3) es notoriamente insuficiente para atender a las necesidades del sistema teniendo en cuenta los propósitos y metas que tuvo la legislación al ser sancionada ${ }^{17}$, aun cuando se destine el tope máximo previsto en la actualidad para el funcionamiento de los Consorcios, cosa que no ha sucedido regularmente.

En cuanto a la norma salteña, rescatamos la configuración de un modelo que no pretende ser lo que no puede ser, ya que otorga a estas estructuras el carácter de personas de Derecho

\footnotetext{
${ }^{15}$ En este sentido, es importante remarcar que adoptar el carácter de persona jurídica privada para los consorcios, aun cuando exista una importante participación del Estado como en el caso que analizamos, no exime a las estructuras de conformar su constitución, sus elementos y su funcionamiento a la ley de fondo. Además, tal atribución restringe la posibilidad del Estado Provincial de regular cuestiones relacionadas con dicha naturaleza, en razón de pertenecer a materias y ámbitos legislativos que son privativos del Congreso Nacional, como lo son aspectos de la responsabilidad y atributos básicos de la persona, como lo es su patrimonio (Ruiz, 2017).

${ }^{16}$ De hecho, si relevamos las últimas novedades respecto a la implementación y funcionamiento del régimen de los últimos 5 años, observaremos que una alta proporción de las notas periodísticas sobre el tema hacen referencia a reclamos por atraso en el envío de fondos indispensables para la subsistencia del sistema (Ruiz, 2017), como ejemplos: "Consorcios productivos rurales reclaman la transferencia de fondos y la adaptación de la ley 6547" (Ahora Ley N 1825-I) (Fuente: https://www.novachaco. com/nota.asp?n=2016_9_29\&id=29737\&id_tiponota=30). "Consorcios productivos rurales reclaman al ejecutivo transferencia de fondos y modificacion de la ley 6547" (Ahora Ley N² 1825-I) (Fuente: http://tresisletas.info/consorcios-productivos-rurales/). 21/12/2016: "Consorcios Productivos de Servicios Rurales reclaman el pago del Fondo Algodonero". (Fuente: http://chaque. nearural.com/ampliar.php?id=36096). 12/04/2015: "Consorcios Rurales denuncian que el Gobierno no cumple con amparo judicial y que no pueden gestionar fondos" (Fuente: http://www.diariochaco.com/noticia/consorcios-rurales-denuncian-queel-gobierno-no-cumple-con-amparo-judicial-y-que-no-pueden). "Consorcios productivos, a punto de estallar, piden la urgente transferencia de fondos" (Fuente: http://www.diarionorte.com/article /145292 /consorcios-productivos-a-punto-de-estallarpiden-la-urgente-transferencia-de-fondos). 20/03/2017: "Consorcios rurales protestan sobre la ruta 9: Trabajadores de la zona rural de El Impenetrable piden la trasferencias de fondos provinciales. "Ya no tenemos sustento" (Fuente: https://www. eldiariodelaregion.com.ar/articulo/consorcios-rurales-protestan-sobre-la-ruta-9_sp8busxu5z/).

${ }^{17}$ Ellos pueden leerse en la transcripción taquigráfica de la sesión ordinaria en la que esta ley fue sancionada por unanimidad de los legisladores presentes.
} 
Público no Estatal y las financia en cuanto tal. Al ser una normativa amplia que incluye diversos tipos de consorcios y no solo los productivos, no es pertinente la crítica sobre la falta de mecanismos que apunten a un verdadero fortalecimiento institucional de un sector económico-productivo determinado (ya que la norma no se propone este objetivo), cuestión que sí se plantea como central en la norma chaqueña.

Si bien la ley salteña es una ley general sobre consorcios, que convive a la vez con otras leyes específicas, como es el caso de la normativa salteña sobre los consorcios de aguas, su objetivo es establecer el procedimiento de creación y financiamiento de una estructura jurídica (que instrumenta la articulación de actuación público-privada) para delegar el desarrollo de funciones que eran tradicionalmente prestadas por los Estados Provinciales o Municipales.

Los Consorcios de Gestión y Desarrollo bonaerenses constituyen un tipo de consorcio que posee caracteres de los dos modelos antes vistos: su objeto específico es el fomento y acompañamiento del desarrollo de actividades productivas agropecuarias locales (similar al esquema chaqueño), pero se estructura en base una figura de derecho administrativo con la participación central de los Municipios, donde el papel de los privados en el manejo de estas entidades parece ser bastante secundario en comparación al papel protagónico que ocupan en el caso de la ley del Chaco.

$\mathrm{Al}$ igual que en los dos casos anteriores, el financiamiento de las estructuras bonaerenses es instrumentada total o prevalentemente a través de mecanismos estatales: asignaciones presupuestarias especiales, asignación de fondos nacionales, internacionales o provinciales destinados a este tipo de actividades. Como en las otras normativas, la viabilidad y supervivencia de estas estructuras queda supeditada a la "voluntad política" de sus responsables ejecutores, minando de este modo los propios objetivos que se tuvieron en miras para su creación, principalmente en el caso chaqueño y bonaerenses, donde se propicia de modo concreto el objetivo de propender a un desarrollo armónico de las regiones.

A partir de todo lo expuesto sobre los modelos normativos provinciales, debemos señalar que la adopción del término "consorcio" es multívoca, siendo utilizada para designar estructuras diseñadas para articular actores públicos y privados.

Algunas normas plantean la figura del consorcio como el instrumento para impulsar el desarrollo productivo local y proveer a la sustentabilidad de los emprendimientos locales. Este es el caso de los modelos consorciales propuestos en las leyes bonaerenses y de la provincia del Chaco. En otros casos, los consorcios se utilizan para descentralizar actividades y funciones que se encuentran originalmente en cabeza del estado en alguno de sus niveles, como ser el cuidado de caminos, el mantenimiento de canales de riego, la distribución y control en el uso del agua, entre muchas otras funciones adjudicadas. La ley $\mathrm{N}^{\circ} 6845$ sobre "Principios para la Organización de Consorcios" de Salta se identifica con este modelo. También este último es el caso de normativa específica de consorcios de riego y de consorcios camineros, que no fueron objeto de estudio pormenorizado en el presente trabajo. 
En el caso de los consorcios como instrumentos de desarrollo local las estructuras diseñadas para promover el desarrollo productivo se encuentran con diversas dificultades que condicionan fuertemente su éxito. Desde nuestro punto de vista, las más serias se relacionan con la alta dependencia de los fondos públicos unido a la falta de mecanismos que tiendan progresivamente a disminuirla, para que, paulatinamente, sea reemplazada por formas autosustentables de mantenimiento. Otro problema no menor lo constituyen los exiguos fondos públicos que se terminan destinando al funcionamiento del sistema consorcial, cuestión que resulta más grave cuando revisamos los objetivos que se proponen alcanzar con dicho financiamiento.

El segundo supuesto -el de los consorcios destinados a la descentralización de funciones propiamente estatales-; padecen también de forma muy frecuente severos problemas de financiamiento por la falta de envío de asignaciones presupuestarias. Además, el correcto funcionamiento de estos últimos muchas veces termina dependiendo del nivel de involucramiento de sus miembros, del afectio societatis del grupo y del conocimiento y respeto por la institucionalidad que posean. Esto provoca que el efectivo cumplimiento de actividades inmanentemente estatales como lo son el mantenimiento de caminos o de canales de riego, termine dependiendo de la calidad del grupo de privados que ejerce circunstancialmente la función en el consorcio.

Corresponde entonces reconocer que más allá de los reparos técnicos-jurídicos específicos que puedan plantearse sobre el modo de estructuración o diseño legislativo las figuras analizadas poseen una serie de problemas que les son comunes y que se presentan como obstáculos o deficiencias de envergadura.

Seguidamente nos detendremos en el análisis de las dificultades comunes que los estudiosos detectan en estas estructuras, no sin antes aclarar que este y otros tantos modelos de articulación público-privada que empezaron a surgir en la normativa nacional y provincial a partir de la década de los noventa están nutridos de los aportes de las teorías del desarrollo local (Choconi, 2003)..$^{18}$

Gorenstein (2004) en un trabajo donde estudia las transformaciones rurales e institucionales en Argentina, describe y analiza estas "experiencias asociativas entre municipios de base

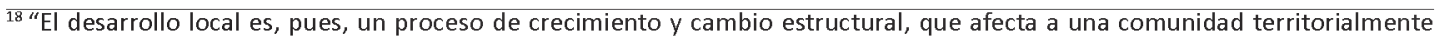
definida, $v$ que se concreta en una mejora del nivel de vida de sus habitantes (Vázquez Barquero, 1988: 26; Hierro Recio, 2000: 62; Alburquerque, 1996b: 47-49). Pero ese proceso no es una simple inercia de las estructuras productivas, sino que requiere una implementación de políticas que la activen y, dichas políticas, incluyen aspectos que van más allá de lo estrictamente económico, para abarcar cuestiones sociales, culturales e incluso políticas." (García Docampo, 2007, p. 17). “Los objetivos de las políticas de desarrollo local deben derivarse de las estrategias establecidas en cada uno de los diferentes territorios las cuales, a su vez, deberían involucrar elementos de coherencia con las políticas a nivel Estado. No hay recetas únicas en este terreno, pero entre dichos objetivos encontraremos los orientados a: i) estimular y detectar iniciativas productivas; ii) facilitar el acceso concertado a los servicios avanzados a la producción por parte del tejido empresarial local; iii) establecer mecanismos de financiación de nuevas empresas y una oferta de crédito apropiada para PYMES y microempresas; e iv) incentivar la cooperación interempresarial en el ámbito territorial." (....) "En otras palabras, las políticas de desarrollo local implican una coherencia mucho mayor con los procesos de descentralización y la difusión territorial del crecimiento económico. Mediante este tipo de políticas se contempla el desarrollo económico como un proceso donde no están ausentes ni el medioambiente ni los actores sociales y su movilización en el territorio, con sus consensos, disensos y conflictos." (Alburquerque Llorens, 1995, p. 23).
} 
agroalimentaria, desarrolladas durante la década del '9o" (p.1), donde refiere específicamente a los Consorcios Productivos Bonaerenses y resume una serie de dificultades para la viabilidad de estas estructuras (Gorenstein, 2004, p.5):

- El predominio de una cultura política localista que rodea a las gestiones públicas, las que se cierran selectivamente ante determinados actores, aun cuando estos formen parte del mismo consorcio productivo.

- Las débiles y deficientes capacidades gerenciales de los gobiernos municipales (en muchos casos extrapolable a gobiernos provinciales). Señala en sentido similar Posada (1999) que se observa en estas estructuras una marcada tendencia de sus miembros a depositar el poder de decisión y gestión de toda la estructura en pocas manos (presidente o coordinador y su entorno), no siempre capacitadas para ejercer todas las funciones necesarias. Adicionalmente, constató una falta de alternancia en los puestos políticos, a pesar de que en la mayoría de los casos los reglamentos o estatutos prevén que estos cargos deberían rotar cada año.

- La heterogeneidad interlocal (diferencias poblacionales, grado de diversificación productiva y económica y cultural, principalmente en los casos de consorcios conformados por diferentes distritos municipales), que provoca contradicciones y conflictos en el proceso de definición de estrategias y acciones.

- El desconocimiento institucional de las tramas productivas y de los privados acerca del modo de funcionamiento de los entes.

- La grave confusión existente en estas estructuras entre políticas asistenciales (orientadas al acceso al trabajo vía promoción del autoempleo) y las de fortalecimiento empresarial en las tramas regionales. Esta confusión ha llevado a la selección de actores destinatarios o beneficiarios que no cumplen con los parámetros y niveles mínimos de capacidad empresarial necesarios para generar dinámicas competitivas, traduciéndose esta disociación en numerosísimos fracasos (desaparición de emprendimientos promocionados), superpoblación de rubros productivos y elevada capacidad ociosa del equipamiento subsidiado. Al igual que Gorenstein, Posada (1999) manifiesta que los fondos crediticios no siempre terminaron siendo destinados al apoyo concreto de actividades agrícolas, y cuando sí se hizo, las adjudicaciones de fondos se efectuaron sin adecuados análisis de factibilidad, lo que dio como resultado la entrega de partidas a emprendimientos que carecían de mínimos requisitos de viabilidad. Asimismo, los canales de asignación frecuentemente fueron poco claros y no se controló la ejecución. Todo ello deja entrever una severa tendencia a tomar estos programas y fondos en un sentido o "perfil más de asistencialismo clientelar, que para el desarrollo rural/local" (Posada, 1999, p.342). Indica además que los fondos entregados fueron insuficientes para generar algún tipo de desarrollo local, sumado ello a la puja por el reparto, la inhabilidad administrativa, los problemas de contra- 
lor, las dificultades para la rendición de cuentas y otras varias cuestiones, contribuyeron a que "el dinero sea solo un estímulo aglutinante" (p.342).

- Por último, Gorenstein resalta un elemento presente en la dinámica de estas estructuras a la que califica como "perverso": la presencia de los efectos de un comportamiento sumido en la lógica político-partidaria, asociada a la acumulación de poder territorial. La presencia de este fenómeno, combinado con las limitaciones del proceso de descentralización, parecen explicar -según esta autora- la desarticulación y fragilidad de sus estructuras. En tal sentido, en algunas experiencias provinciales la intervención de Instituciones distintas del ámbito estatal como las Universidades Públicas, reveló la importancia de estos actores, los que, generalmente, priorizan la gestión técnica antes que política del proceso. En una línea argumental similar Posada (1999) señala críticamente que la organización y funcionalidad de estos entes en los hechos termina directamente relacionada con la afiliación político-partidaria de las intendencias que participan, socavando las bases sobre las que se constituyen estas estructuras.

Concluye Gorenstein (2004) finalmente que éstos (...) ofrecen un testimonio importante sobre la debilidad de las capacidades locales y puede dar algunas pistas acerca de las dificultades que se presentan para la construcción de formas de gobernabilidad territorial que faciliten la promoción y apoyo a los procesos de desarrollo rural (p.1).

Por lo tanto, sin desconocer que estos diseños institucionales aspiraron a convertirse en espacios micro-regionales que coordinan "sinergias" público-privadas, la mayoría de ellos fueron desarrollados exclusivamente por la iniciativa de las entidades estatales, inducidos en gran medida por la necesidad de captación de recursos, y no como consecuencia de una planificación estatal nacional o provincial para el desarrollo regional, por lo que en la realidad solo se trataron de formas jurídico-administrativas cuyo objeto fue posicionarse de manera más ventajosa ante el poder nacional y provincial al momento de disputar una mayor asignación de recursos (Choconi, 2003). Definida su razón de ser en estos términos, "los consorcios existieron en cuanto tales en tanto hubo una oferta de programas dirigidos a ellos" (Choconi, 2003, p.20).

Asimismo, al tratarse de una política "centrada exclusivamente en el Estado, los efectos en términos de difusión fueron inexistentes (...)" (Choconi, 2003, p.21). A tal punto que en algunos casos estos entes ni siquiera ejecutaban acciones como algo diferente de los municipios, y su escasa actividad desplegada se concentró en pequeños proyectos productivos poco significativos para la región y la provincia-. Por todo ello concluye que a pesar de contemplarse la participación de los privados en la normativa, en la experiencia prevaleció la presencia del Municipio en desmedro del involucramiento del sector privado, lo que "inhibió la generación 
de actores asociados "potenciadores de sinergias locales" (Lisio, 1999 y Gorensetin, 1998, citadas en Choconi, 2003, p.21).

Sin perjuicio de las observaciones anteriores, resalta Posada (s/f, pp.12-14) que del panorama descripto es posible inferir algunas cuestiones que serían útiles para el diseño de políticas futuras:

- Existe predisposición para la constitución de entidades intermunicipales.

- El otorgamiento de fondos subsidiados por sí solo no alcanza para generar algún tipo de desarrollo local, por lo tanto el dinero no debe ser la única razón de la conformación de los consorcios o la presentación de proyectos.

- La importancia de la suficiencia de los fondos asignados. Efectivamente, una vez adjudicados, los fondos también se tornan un problema con el pasar del tiempo: no sólo por las cuestiones relativas a las rendiciones, sino también porque buena parte se destina a proyectos que requieren en la realidad una suma mayor que la que efectivamente recibieron para poder cumplir con los objetivos propuestos.

- La importancia de un correcto estudio de factibilidad y la necesidad de ejercer un seguimiento y control de la ejecución: muchas veces se destinaron créditos a actividades inviables o no se controló su ejecución, por lo que existió una tendencia a utilizar el dinero en fines no productivos.

- La importancia del afianzamiento de prácticas democráticas al interior de los organismos intermunicipales y de las estructuras consorciales, así como la necesidad de promover la especialización de sus funcionarios.

- Finalmente, es conveniente destacar un factor decisivo para comenzar a recorrer el camino del desarrollo rural global: el diseño y la implementación de políticas diferenciadas que engloben a la totalidad del sistema y no solamente lo estrictamente productivo.

En síntesis, creemos que no se debe descartar la utilidad de las experiencias provinciales debido a las fallas estructurales y dificultades funcionales señaladas, sino que resulta necesario aprender de ellas para lograr modelos superadores que aprovechen sus fortalezas y trabajen en minimizar los aspectos negativos.

Porque, como apunta Posada (s/f) refiriéndose a estas experiencias “(...) en ella[s] se encierran dos precondiciones básicas para el desarrollo rural moderno, la persistencia del eje productivo agropecuario y la cooperación intermunicipal” (p.16). Sumado a que "(...) la opción política por las actividades agropecuarias constituye un elemento positivo sobre el que podría asentarse una política activa y específica de desarrollo rural" (p.13) y el que es necesario no desaprovechar. 


\section{REFERENCIAS BIBLIOGRÁFICAS}

Albureque Llorens, F. (1995). Espacio, Territorio y Desarrollo Económico Local. CEPAL. Santiago. Recuperado de: https://repositorio.cepal.org/

Boretto, M. (2015). Código Civil y Comercial de la Nación Comentado. Gustavo Caramelo, Sebastián Picasso, Marisa Herrera (Dirs.) 1a ed. T1, p. 299. Infojus: Ciudad Autónoma de Buenos Aires.

Choconi, S. (2003). Algunas ideas críticas sobre el desarrollo local; el caso de los consorcios productivos en la provincia de Buenos Aires-Argentina. Problemas del Desarrollo, Distrito Federal, México, Instituto de Investigaciones Económicas (IIEc). Universidad Nacional Autónoma de México (UNAM), Vol. 34, Núm. 135, pp. 9-27. Recuperado de: http://biblioteca. municipios.unq.edu.ar/modules/mislibros/archivos/choconi.pdf

Gorenstein, S. (2004). La visión desde las cadenas agroalimentarias. Seminario-Taller "Transformación productiva e institucional del mundo rural en Argentina", Buenos Aires.

Posada, M. (1999). Desarrollo Rural y Desarrollo Local: un estudio de caso en la Argentina. Revista Espacio Abierto, septiembre-diciembre, año/vol. 8, número oo3. Asociación Venezolana de Sociología Maracaibo, Venezuela pp. 325-346. Recuperado de: http://biblioteca.municipios. unq.edu.ar/modules/mislibros/archi vos /12208303.pdf

Posada, M. (s/f). Desarrollo rural y Desarrollo local. Los primeros pasos de los consorcios productivos de la Provincia de Buenos Aires. Recuperado de: http://biblioteca.municipios. unq.edu.ar/modules/mislibros/archivos/consorcios\%20municipales-Posada.PDF

Ruiz, H. (2017). Los Consorcios Productivos de Servicios Rurales de la Provincia Del Chaco. IV Congreso Nacional de Derecho Agrario Provincial (Salta, 2017). Recuperado de: http://hdl. handle.net/10915/60445

Tévez, A. (2015). Código Civil y Comercial de la Nación comentado. Gustavo Caramelo, Sebastián Picasso, Marisa Herrera (Dirs.) 1a ed. T4, p. 179. Infojus: CABA. 


\section{CURRICULUM VITAE}

\section{Haraví Eloísa Ruiz}

Doctora en Derecho por la Facultad de Derecho, Ciencias Sociales y Políticas (UNNE). Especialista en Docencia Universitaria y Teoría y Práctica del Proceso Judicial (UNNE). Jefe de Trabajos Prácticos por concurso de la Cátedra A de Derecho Agrario y Ambiental de la Facultad de Derecho de la UNNE. Becaria Posdoctoral UNNE-CONICET.

haraviruiz@gmail.com 